\title{
PERSPECTIVE
}

\section{Policies Sanctioning Discrimination Against Transgender Patients Flout Scientific Evidence and Threaten Health and Safety}

\author{
Aron Janssen ",* and Raina Voss' ${ }^{2}$; Written on behalf of the Gender Development Program at the Ann and Robert H. Lurie \\ Children's Hospital of Chicago
}

Keywords: transgender; public policy and advocacy; barriers to care; health disparities

Access to equitable and evidence-based health care for transgender people is increasingly under threat across the United States. The Trump administration has engaged in broad efforts to limit the rights of transgender Americans and multiple conservative-led state congressional proposals have attempted to make treatment of transgender youth with hormones and puberty blockers a criminal offense. In June, 2020, the Department of Health and Human Services (DHHS) finalized a rule eliminating protections against health care discrimination based on gender identity. ${ }^{1}$ This protection from health care discrimination was previously afforded by section 1557 of the Affordable Care Act (ACA), with guidance by the Obama administration explicitly stating that transgender individuals were protected by this section. With last week's rule change, DHHS has granted health care facilities, insurers, and providers the right to deny transgender patients care simply because of their gender identity. ${ }^{2}$

These malicious changes target a highly vulnerable population and provide fodder to perpetuate discrimination, fear, and exclusion. It is our ethical responsibility as health care providers to respond to this assault, and we will rebut the administration's claims based on the science of gender identity, the evidence in support of affirming care for transgender patients, and the language of the rule change itself.

\section{Science of Gender Identity}

Gender identity (including both cisgender and transgender identity) is self-evident and requires no justification or explanation. And yet, we must address the pseudoscience advanced by this administration. As aforementioned, in justifying the rule change for section 1557 of the ACA, the administration defines sex as male or female as determined by biology. Although not explicitly stated, it is implied that biology in this context is defined by what one's genitals look like at birth, rather than reflecting the complex process of gender development that involves genes, hormones, brains, bodies, and experiences. This narrow-minded thinking disregards decades of research in developmental neuroscience that has sought to understand the biological underpinnings of gender development. ${ }^{3}$ Contrary to what this administration may state, our brains are very much a part of our biology.

\section{Evidence for Affirming Care for Transgender Patients}

Transgender people face undue health burden and risk stemming from pervasive discrimination. Undoubtedly, these risks are anticipated to worsen as structural barriers to care increase. ${ }^{4}$ Among transgender adults, $22 \%$ (32\% among people of color) have no health insurance as compared with $12 \%$ of all adults. ${ }^{5}$ Even for those with insurance, $70 \%$ of transgender adults have faced discrimination in medical care and $27 \%$ have been refused the care that they need. ${ }^{6}$ Nearly a quarter avoided the doctor because of fear of mistreatment and denials of life-saving care are routine. $^{7}$

This stigma and bias has led to chronic mental and physical health disparities among the transgender

Departments of ${ }^{1}$ Psychiatry and ${ }^{2}$ Pediatrics, Ann and Robert H. Lurie Children's Hospital of Chicago, Chicago, Illinois, USA.

*Address correspondence to: Aron Janssen, MD, Department of Psychiatry, Ann and Robert H. Lurie Children's Hospital of Chicago, 225 E. Chicago Avenue, Chicago, IL 60611, USA, E-mail: ajanssen@luriechildrens.org 
population. In transgender youth, one third of those seeking care had depression with more than half having contemplated suicide. ${ }^{8}$ Substance use rates were uniformly higher than in cisgender peers, as were high-risk sex behaviors and rates of experiencing physical violence $(24 \%)$ and sexual violence $(24 \%){ }^{9}$ Among transgender adults, disparities continue to accumulate. Forty percent of transgender adults have attempted suicide. ${ }^{7}$ There is an HIV prevalence of $14.1 \%$ among transgender women and $44 \%$ among black transgender women. ${ }^{10}$ Transgender adults have rates of cigarette smoking that are $50 \%$ higher than the general population. ${ }^{11}$

As providers caring for transgender youth, the treatment we provide is rooted in evidence demonstrating that individuals with access to care have improved mental health outcomes ${ }^{12,13}$ and reduced suicidality. ${ }^{14}$ Section 1557's previous protections for transgender Americans provided access to affirming medical and mental health care for countless citizens and removing these protections will lead to worsening outcomes and increased death.

\section{Language of the Rule Change}

The Trump administration describes the rule change to section 1557 as a reversion to the "plain meaning" of the word "sex" and justifies this change by arguing that discrimination on the basis of sex has never included gender identity. However, just 3 days after the Trump administration made this claim, the Supreme Court ruled in an employment discrimination case that "discrimination based on homosexuality or transgender status necessarily entails discrimination based on sex." ${ }^{\prime 5}$ We urge DHHS to re-examine their flawed logic and look to this guidance provided by their judicial counterparts for an understanding of a clearer definition of discrimination based on sex.

Furthermore, DHHS claims that their regulatory change "omits overboard provisions related to sex and gender identity." We would ask the administration, what "overboard provisions related to sex and gender identity" are you seeking to omit? Based on the aforementioned health disparities, if anything, protections against discrimination for transgender people should be strengthened.

\section{Conclusion}

Our patients are afraid. After Trump was elected, we held space for them as they expressed fear that they would not be able to access life-saving gender-affirming care. We have watched their journeys as our country has at once made strides forward in understanding best practices to support transgender patients, and simultaneously, our leaders have made concerted efforts to stand in the way of this care. Our patients and their families, already unduly stressed by the global COVID pandemic and the recent escalation in police violence, are now feeling their health and safety being threatened on yet another level.

Federal rule changes to the ACA that eliminate protections against discrimination are a threat to the health of transgender youth and adults. These initiatives directly oppose the evidence-based care recognized by professional societies across multiple disciplines (AAP, AMA, Endocrine Society, WPATH, and AACAP). The changes are based on flawed logic and an effort to oppress. We urge providers to seek out, rather than turn away from, opportunities to better understand the unique health risks and needs of transgender patients to continue to improve care delivery. We will continue to provide the highest level of care and advocate for our patients as they surmount the ever-changing barriers created for them by the American health care system.

\section{Author Disclosure Statement}

Neither Dr. Janssen nor Dr. Voss report any commercial associations that might create a conflict of interest in connection with this article.

\section{Funding Information}

No funding was received for this article.

\section{References}

1. HHS Press Release. Available at: https://www.hhs.gov/about/news/2020/ 06/12/hhs-finalizes-rule-section-1557-protecting-civil-rights-healthcare .html Accessed June 18, 2020.

2. HHS Fact Sheet. Fact Sheet: HHS Finalizes ACA Section 1557 Rule. Office of Civil Rights. 2020. Available at: https://www.hhs.gov/sites/default/files/ factsheet-section-1557.pdf Accessed June 18, 2020.

3. Roselli CE. Neurobiology of gender identity and sexual orientation. J Neuroendocrinol. 2018;30:e12562.

4. Nuttbrock L, Bockting W, Rosenblum A, et al. Gender abuse, depressive symptoms, and HIV and other sexually transmitted infections among male-to-female transgender persons: a three-year prospective study. Am J Public Health. 2013;103:300-307.

5. Centers for Disease Control, Behavioral Risk Factor Surveillance System. 2018.

6. Lambda Legal, When Health Care Isn't Caring: lambda Legal's Survey of Discrimination Against LGBT People and People with HIV. 2010. Available at: www.lambdalegal.org/health-care-report Accessed June 18, 2020.

7. James SE, Herman J, Keisling M, et al. 2015 U.S. Transgender Survey (USTS). Ann Arbor, MI: Inter-university Consortium for Political and Social Research. 2019 
8. Olson J, Schrager S, Belzer M, et al. Baseline physiologic and psychosocial characteristics of transgender youth seeking care for gender dysphoria. J Adolesc Health. 2015;57:374-380.

9. Johns MM, Lowry R, Andrzejewski J, et al. Transgender identity and experiences of violence victimization, substance use, suicide risk, and sexual risk behaviors among high school students-19 states and large urban school districts, 2017. MMWR Morb Mortal Wkly Rep 2019; 25;68:67-71.

10. Becasen JS, Denard C, Mullins M, et al. Estimating the prevalence of HIV and sexual behaviors among the US transgender population: a systematic review and meta-analysis, 2006-2017. Am J Public Health. 2019;109:e1-e8.

11. Grant JM, Mottet LA, Tanis J, et al. Injustice at Every Turn: a Report of the National Transgender Discrimination Survey. Washington, DC: National Center for Transgender Equality and National Gay and Lesbian Task Force, 2011.

12. Olson KR, Durwood L, DeMeules M, McLaughlin KA. Mental health of transgender children who are supported in their identities. Pediatrics. 2016;137:e20153223.

13. de Vries A, McGuire J, Steensma T, et al. Young adult psychological outcome after puberty suppression and gender reassignment. Pediatrics 2014;134:696-704.
14. Turban J, King D, Carswell J, Keuroghlian A. Pubertal suppression for transgender youth and risk of suicidal ideation. Pediatrics. 2020;145: e20191725.

15. Bostock vs. Clayton County, 590 U.S. 19 (2020).

Cite this article as: Janssen A, Voss R (2021) Policies sanctioning discrimination against transgender patients flout scientific evidence and threaten health and safety, Transgender Health 6:2, 61-63, DOI: $10.1089 /$ trgh.2020.0078.

\section{Abbreviations Used}

$\mathrm{ACA}=$ Affordable Care Act

DHHS $=$ Department of Health and Human Services 